\title{
Professional Identity of Applicants and Students in the System of Higher IT Education of Ukraine
}

\author{
Tetiana Kovaliuk ${ }^{1}$, Nataliya Kobets ${ }^{2}$ \\ ${ }^{1}$ Taras Shevchenko National University of Kyiv, Ukraine \\ ${ }^{2}$ Borys Grinchenko Kyiv University, Ukraine
}

\begin{abstract}
The article considers the methodological problem of forming the professional identity of entrants and students in the transition to a knowledge society. It is shown that the choice of profession takes into account the dynamics of professional development of the individual, associated with the formation of his professional identity and the process of professional selfdetermination. The analysis of the factors influencing the choice of profession by young people was studied on the example of IT professions. The article lists the most popular IT professions in 2021. In accordance with the trends of interaction between IT education and the IT industry, the trends in the development of higher education in Ukraine and their impact on the formation of professional self-awareness of young people are described. The authors consider the professional identity of the individual as one that develops as a result of his work or educational activities. The paper analyzes the factors that contribute to the formation of the professional identity of applicants. The article proves that the choice of university entrants is a factor influencing their professional self-determination. The choice of the educational program by the entrants is considered as a factor of their professional self-realization, and the formation of the individual educational trajectory of the student is considered as a factor of realization of the "I-concept" at the level of determining professional preferences of entrants. The article analyzes the dynamics of change in the professional identity of entrants and students on the example of training in the speciality "Software Engineering" at different stages of becoming a competent specialist. The dynamics of the development of a student's professional identity from student identification "I-student" to European identity as a condition of integration into the European community is shown.
\end{abstract}

Keywords: educational program, individual educational trajectory, professional selfdetermination, professional self-realization, professional identity. 